\title{
What should be done in patients diagnosed with xanthogranulomatous cholecystitis? Case-control study
}

\author{
Tolga Canbak, (D) Aylin Acar, (D) Huseyin Kerem Tolan \\ Department of General Surgery, Health Sciences University, Umraniye Training and Research Hospital, Istanbul, Turkey
}

\begin{abstract}
OBJECTIVE: In this study, we aimed to compare development of complications, malignancy and confusion rates in the preliminary diagnosis in patients with xanthogranulomatous cholecystitis identified.

METHODS: In this study, 2803 patients undergone cholecystectomy between January 2010 and December 2016 were retrospectively evaluated. Patients with xanthogranulomatous cholecystitis identified in the histopathological examination were classified as Group 1 and patients with cholelithiasis, cholecystitis, and malignancy detected were classified as Group 2.

RESULTS: Forty-five patients with xanthogranulomatous cholecystitis were classified as group 1 and 2758 patients as group 2. of group 1, 18 were male and group 2 consisted of 2758 patients with $707(26 \%)$ being male $(p=0.04)$. In the ultrasonographic examination, the wall thickness was increased in 40 patients in Group 1 and 662 patients in Group $2(p<0.0001)$. The operation was converted to the open type in 24 patients in Group 1 and 61 patients in Group $2(p<0.0001)$. Five patients in Group 1 and 32 patients in Group 2 developed complications in the postoperative period $(p<0.0001)$.

CONCLUSION: Xanthogranulomatous cholecystitis should be considered for the differential diagnosis and the operation should be performed, especially by carefully exposing the anatomy in these patients.

Keywords: Cholecystitis; cholecystectomy; xanthogranulomatous.

Cite this article as: Canbak T, Acar A, Tolan HK. What should be done in patients diagnosed with xanthogranulomatous cholecystitis? Case-control study. North Clin Istanb 2020;7(5):467-470.
\end{abstract}

X anthogranulomatous cholecystitis is a rare variant of cholecystitis characterized by focal or diffuse inflammatory changes $[1,2]$. It is usually accompanied by thickening of the bile duct wall, inflammatory infiltration, and diffusion into the liver [3].

In this study, we aimed to compare the development of complications, malignancy and confusion rates in the preliminary diagnosis in patients with xanthogranulomatous cholecystitis identified and those undergone cholecystectomy with other indications in histopathological examination of large series including patients with a large number of cholecystectomy procedures performed.

\section{MATERIALS AND METHODS}

In this study, 2803 patients undergone cholecystectomy in an Education and Research Hospital, Department of General Surgery in a 7-year period between January 2010 and December 2016 were retrospectively evaluated. Ethics committee approval was not required because this was a retrospective study. Patients who underwent cholecystectomy and resection of segment 4-5 of the liver due to preoperative bile duct tumors, pregnant patients, those in whom the operation could not be laparoscopically initiated, and the patients who rejected participation were excluded from the study.

Received: August 27, 2019 Accepted: March 02, 2020 Online: September 01, 2020

Correspondence: Aylin ACAR, MD. Saglik Bilimleri Universitesi, Umraniye Egitim ve Arastirma Hastanesi, Genel Cerrahi Klinigi, Istanbul, Turkey.

Tel: +90216 6321818 e-mail: aylinacar79@hotmail.com

(c) Copyright 2020 by Istanbul Provincial Directorate of Health - Available online at www.northclinist.com 
Patients were grouped based on the histopathological examination outcomes. Patients with xanthogranulomatous cholecystitis identified in the histopathological examination were classified as group 1 and those with cholelithiasis, cholecystitis, cholelithiasis and malignancy detected were classified as group 2. All patients gave verbal and written consent. Intravenous single dose $2^{\text {nd }}$ generation cephalosporin was preoperatively administered. Whereas the operation was started as standard laparoscopy in all patients, cholecystectomy was performed using the right subcostal incision in the patients where the operation cannot be laparoscopically continued. The groups were compared concerning demographics, presence of icterus, morbidity, laboratory outcomes, imaging studies, gallbladder wall thickness, conversion rates and the development of postoperative complications.

\section{Statistical Analysis}

All statistical analyses were performed using SPSS 22.0 statistical package software (SPSS, Inc., Chicago, IL, USA). Categorical variables were presented as medians, frequencies and percentages. Chi-square test was used for comparison of continuous parametric variables. $p$ values $<0.05$ were considered statistically significant.

\section{RESULTS}

In this study, 2803 patients undergone laparoscopic cholecystectomy in the Education and Research Hospital, Department of General Surgery were retrospectively evaluated. Patients were divided into groups according to the histopathological examination outcomes. Forty-five patients with xanthogranulomatous cholecystitis detected in the histopathological examination were classified as group 1 and 2758 patients with cholelithiasis, cholecystitis, biliary pancreatitis or malignancy as group 2 . The incidence of xanthogranulomatous cholecystitis was $1.6 \%$ in the patients undergone cholecystectomy.

Group 1 included 45 patients. Of these, 18 (40\%) were male and $27(60 \%)$ were female patients. Group 2 consisted of 2758 patients with 707 (26\%) being male and 2051 (74\%) female. There was a statistically significant between the groups in terms of gender $(p=0.04)$. The mean age was found as 54.79 in group 1 and 48.7 in group 2. Comorbidity was observed in 19 (42\%) patients in group 1 and $827(30 \%)$ patients in group $2(\mathrm{p}=0.10)$. Leukocytosis was detected in $25(55.5 \%)$ patients in group 1 and $275(9.9 \%)$ patients in group 2 . There was a statistically
TABLE 1. Comparison of groups' demographic data and laboratory results

\begin{tabular}{lccc} 
& $\begin{array}{c}\text { Group } 1 \\
\%\end{array}$ & $\begin{array}{c}\text { Group } 2 \\
\%\end{array}$ & $\mathrm{p}^{*}$ \\
& 54.79 & 48.7 & \\
\hline $\begin{array}{l}\text { Age } \\
\text { Gender }\end{array}$ & & & $0.04 * *$ \\
$\quad$ Female & 60 & 74 & \\
$\quad$ Male & 40 & 26 & 0.10 \\
$\begin{array}{l}\text { Presence of morbidity } \\
\text { Leukocytosis }\end{array}$ & 42 & 30 & $<0.0001^{* *}$ \\
\hline
\end{tabular}

*: Chi-square test; **: Statistically significance.

TABLE 2. Comparison of conversion rates between groups and postoperative complication development

\begin{tabular}{lccc} 
& $\begin{array}{c}\text { Group 1 } \\
\%\end{array}$ & $\begin{array}{c}\text { Group 2 } \\
\%\end{array}$ & $\mathrm{p}^{*}$ \\
\hline Conversion & 53 & 2.1 & $<0.0001^{* *}$ \\
Postoperative complication & 11.1 & 1 & $<0.0001^{* *}$ \\
\hline
\end{tabular}

*: Chi-square test; **: Statistically significance.

significant difference between both groups in terms of leukocytosis detection rates $(<0.0001)$ (Table 1$)$.

In the ultrasonographic examination, the wall thickness was increased in $40(88.8 \%)$ patients in group 1 and $662(24 \%)$ patients in group 2 . There was a statistically significant difference between the groups $(\mathrm{p}<0.0001)$. Five $(11 \%)$ of the patients in group 1 had suspicion of preoperative malignancy. Intra-operative frozen was sent in 2 of them, which resulted as benign. Preoperative abscess was detected in one patient and cholecystectomy was continued in the remaining two patients since no suspicion of the tumor was seen during the operation. The operation was converted to the open type in 24 (53.3\%) patients in group 1 and $61(2.1 \%)$ patients in group 2. There was a statistically significant difference between the groups in terms of conversion rates $(p<0.0001)$.

Five $(11.1 \%)$ patients in group 1 and 32 (1\%) patients in group 2 developed complications in the postoperative period. A statistically significant difference was found between both groups in terms of the development of complications $(\mathrm{p}<0.0001)$ (Table 2$)$. Postoperative complications in group 1 included wound site infection in 
two patients, pleural effusion in one patient, liver abscess in one patient and biliary fistula and incisional hernia in one patient. In group 2, biliary tract injury was observed in two patients and operated. None of the patients underwent laparoscopy and/or relaparotomy. Mortality was seen in one patient $(2.2 \%)$ in group 1 , while no mortality occurred in any patient in group 2 .

\section{DISCUSSION}

Xanthogranulomatous cholecystitis (XGC) is a rare form of cholecystitis characterized by the accumulation of lipid-loaded histiocytes on the gallbladder wall [4]. In the present study, XGC was found in $1.6 \%$ of the patients who underwent cholecystectomy. XGC is usually seen in middle age or elderly patients [5,6]. Consistently with the literature, the mean age was found as 54.79 in XGC patients and 48.7 in Group 2.

Thickened gallbladder wall due to chronic inflammation, adhesion in the neighboring tissue and organs and even Mirizzi may be seen in xanthogranulomatous cholecystitis [7]. In this study, in the ultrasonographic examination, wall thickness increased in 40 (88.8\%) of patients in group 1 and 662 (24\%) of patients in group 2 . There was a statistically significant difference between the groups $(p<0.0001)$. High rate of increased wall thickness was observed in xanthogranulomatous cholecystitis.

In a study conducted by Guzman-Valdivia G, cholecystectomy could be completed in $65 \%$ of the patients, while partial cholecystectomy could be performed in the remaining 35\% [2]. In the present study, laparoscopic cholecystectomy could be initiated in all patients, but cholecystectomy could be completed in $53.3 \%$ with the conversion.

Differential diagnosis of XGC with gallbladder malignancy is quite challenging. Differential diagnosis can be established through preoperative imaging studies. In intraoperative evaluation, distinction from malignancy may not be carried out macroscopically. Frozen-section should be undertaken in patients where xanthogranulomatous cholecystitis is difficult to distinct from malignancy $[2,8]$. Thus, rates of unnecessary resections can be reduced. In our study, frozen-section was applied in two patients. Microscopically flaky foam cells, fibroblasts and typical granuloma, which consists of inflammatory cells is the gold standard for the pathological diagnosis of xanthogranulomatous cholecystitis $[9,10]$.

Xanthogranulomatous cholecystitis is a benign disease of the gallbladder and although it has a low rate of mortality as in cholecystectomy performed due to other benign cholelithiasis conditions, postoperative complications are more common with this disease [6]. In this study, complications developed in $5(11.1 \%)$ patients with xanthogranulomatous cholecystitis and in 32 (1\%) patients in group 2 in the postoperative period. A statistically significant difference was found between the groups in terms of the development of complications $(\mathrm{p}<0.0001)$. Patients in group 1 developed more complications compared with those in group 2, although when assessed under the title of complications developed, gallbladder tract injury was not observed in group 1 . This could be explained by the larger number of patients in group 2, and carefully performed surgery with experience and comprehensive knowledge of relevant anatomy.

\section{Conclusion}

Surgery of xanthogranulomatous cholecystitis is quite challenging. Intraoperative diagnosis is difficult and thus, frozen-section should be undertaken in the case of clinical suspicion. Additional resections can be avoided with performing frozen-section. Xanthogranulomatous cholecystitis should be considered for the differential diagnosis and the operation should be performed, especially by carefully exposing the anatomy in these patients. Partial cholecystectomy can be carried out in the patients where complete cholecystectomy cannot be performed.

Acknowledgements: We are thankful to Prof. Dr. Fikret Ezberci.

Conflict of Interest: No conflict of interest was declared by the authors.

Financial Disclosure: The authors declared that this study has received no financial support.

Authorship Contributions: Concept - TC, AA, HKT; Design - TC, AA, HKT; Supervision - TC; Materials - TC, AA, HKT; Data collection and/or processing - TC, $A A$; Analysis and/or interpretation - TC, $A A$, HKT; Literature review - TC, AA, HKT; Writing - TC, AA, HKT; Critical review - TC.

\section{REFERENCES}

1. Rajaguru K, Mehrotra S, Lalwani S, Mangla V, Mehta N, Nundy S. New scoring system for differentiating xanthogranulomatous cholecystitis from gall bladder carcinoma: a tertiary care centre experience. ANZ J Surg 2018;88:E34-9. [CrossRef]

2. Guzmán-Valdivia G. Xanthogranulomatous cholecystitis in laparoscopic surgery. J Gastrointest Surg 2005;9:494-7. [CrossRef]

3. Yuan HX, Wang WP, Wen JX, Ji ZB, Ding H, Huang BJ, et al. Xanthogranulomatous cholecystitis: contrast-enhanced ultrasound features and differential diagnosis from wall-thickening gallbladder carcinoma. Discov Med 2016;21:89-98. 
4. Houston JP, Collins MC, Cameron I, Reed MW, Parsons MA, Roberts KM. Xanthogranulomatous cholecystitis. Br J Surg 1994;81:1030-2.

5. Cárdenas-Lailson LE, Torres-Gómez B, Medina-Sánchez S, Mijares-García JM, Hernández-Calleros J. Epidemiology of xanthogranulomatous cholecystitis. [Article in Spanish]. Cir Cir 2005;73:19-23.

6. Guzmán-Valdivia G. Xanthogranulomatous cholecystitis: 15 years' experience. World J Surg 2004;28:254-7. [CrossRef]

7. Lee KC, Yamazaki O, Horii K, Hamba H, Higaki I, Hirata S, et al. Mirizzi syndrome caused by xanthogranulomatous cholecystitis: report of a case. Surg Today 1997;27:757-61. [CrossRef]
9. Pinocy J, Lange A, König C, Kaiserling E, Becker HD, Kröber SM. Xanthogranulomatous cholecystitis resembling carcinoma with extensive tumorous infiltration of the liver and colon. Langenbecks Arch Surg 2003;388:48-51. [CrossRef]

10. Hsu C, Hurwitz JL, Schuss A, Katz DS. Radiology-Pathology Conference: Xanthogranulomatous cholecystitis. Clin Imaging 2003;27:4215. [CrossRef]

11. Krishnani N, Dhingra S, Kapoor S, Pandey R. Cytopathologic diagnosis of xanthogranulomatous cholecystitis and coexistent lesions. A prospective study of 31 cases. Acta Cytol 2007;51:37-41. [CrossRef] 